\title{
The company at university laboratory like efficient means for training of future engineers
}

Vladimir Vasinek, Vladimira Rasnerova, Lukas Hajek, Jan Latal

Vladimir Vasinek, Vladimira Rasnerova, Lukas Hajek, Jan Latal, "The company at university laboratory like efficient means for training of future engineers," Proc. SPIE 11143, Fifteenth Conference on Education and Training in Optics and Photonics: ETOP 2019, 111431X (2 July 2019); doi: $10.1117 / 12.2523894$ Photonics: ETOP 2019, 2019, Quebec City, Quebec, Canada 


\title{
The company at university laboratory like efficient means for training of future engineers
}

\author{
Vladimir Vasinek, Vladimira Rasnerova, Lukas Hajek, Jan Latal \\ All: Technical University of Ostrava, Department of Telecommunications, 17.listopadu 15, Ostrava- \\ Poruba, CR-70833, Czech Republic
}

\begin{abstract}
This contribution describes a solution leading to a higher quality of university study due to the student integration into the activities of the company that creates at the university laboratory. The main benefit is the fact that there is a personal union between people teaching in the laboratory and company employees. This union leads to close cooperation among professors and future engineers both in laboratories during the solution of measurements tasks in optical communications and fiber sensors applications and sw projects and practice during the solution of complicated commissions. These students are obtaining knowledge and skills that is impossible for them to obtain during a typical university study. At the same time, the respect of professors and other teaching people is rising in students because they can see them working. The company is then able to employ the best students as future employees.
\end{abstract}

Keywords: M-Z interferometer, laboratory and company cooperation, optical sensors, study improving

\section{INTRODUCTION}

There are many ways how to join companies in education and training. The way of joining is important primarily in case of the technical university. Graduates from these universities are usually working not as research and development workers, but as engineers and technicians in service at firms and companies. Nowadays endeavor concerning the joining of the company and firm professionals in education and training are heavily supported through many projects and grants, but it acts mostly about "artificial joining" without complying with economic relationships. The cooperations are based on personal acquaintanceships and attachments. Why the direct joining of the companies professionals in education is not functioning well?

1. There is a big lack of suitable personnel in firms and companies. There are typically very good specialists, but they have problems with explanations of complicated problems in a simple way.

2. The course of actions and solution findings are different in firms and companies.

3. It is complicated to harmonize the firm and university dynamics.

4. Legal questions allied with industrial safety of students.

5. The firms and companies are carrying the most of costs, where is their profit?

However, the problems are also on the university side. What is the typical scheme of teacher's and lecturer's creation?

a. The student is coming to university to bachelor study, in our case - Information and communication technology.

b. He meets with educators who have never been in the industry, and they did not know or guessed only, what are the industrial problems, what is the dynamic of acting and ways of thinking.

c. His educators are transmitting him their best; the question remains if it is the best for the student and his future exercise in practice.

d. Students successfully graduate the bachelor study and are coming to the magister degree.

e. The situation with educators is repeating; the students have added the solving of projects that behave as a solving of projects coming from firms and companies. In fact, it is not so.

f. The students graduate successfully their magister studies, part of them continue in firms and companies, and part (usually the better part) is continuing in doctorate study, remain at university, and is teaching.

g. The circle is closing, the new graduates (and future associate professors and regular professors) are teaching the potential engineers and technicians without the knowledge of processes in firms and companies. 
What is the consequence?

Both worlds - company world and the university world are drawing apart quickly. It describes the situation for the Middle and Eastern Europe, where we know the problem, we hope that it does not describe the general state.

\section{OWN COMPANY AS A SOLUTION}

We are trying to display one possible approach to solving this problem in the field of study "Photonics and photonic communications" at our university.



Figure 1. Students during optical fiber preparation for DTS measurement

Our team (under prof. Vasinek leadership) has 17 members in a structure:

One professor

One associate professor

Five assistant professors

Four researchers

Six graduate students

One financial manager

Approximately six years ago, our team was functioning according to scheme mentioned above. We were leading 15-20 students per year that have gone to firms and companies as engineers and technicians and 1-2 students that were continuing in doctorate study.

During our meetings with the many top company management that are employing our students, we were listening to complaints concerning the unsuitable structure of knowledge, ignorance of company processes. We were listening to the good knowledge of photonics and optical communications but poor knowledge of wider contexts.

We are trying to make it clearer on an example of one application of fiber optic sensors for escapes monitoring of dangerous gases from the middle-pressure pipelines, see Figure 1. The solution obtained several awards at the international exhibitions of patents and innovations. 
The principle of solution is based on the cooling of metallic pipelines during the adiabatic expansion that creates during pipeline breakages, Figure 2.

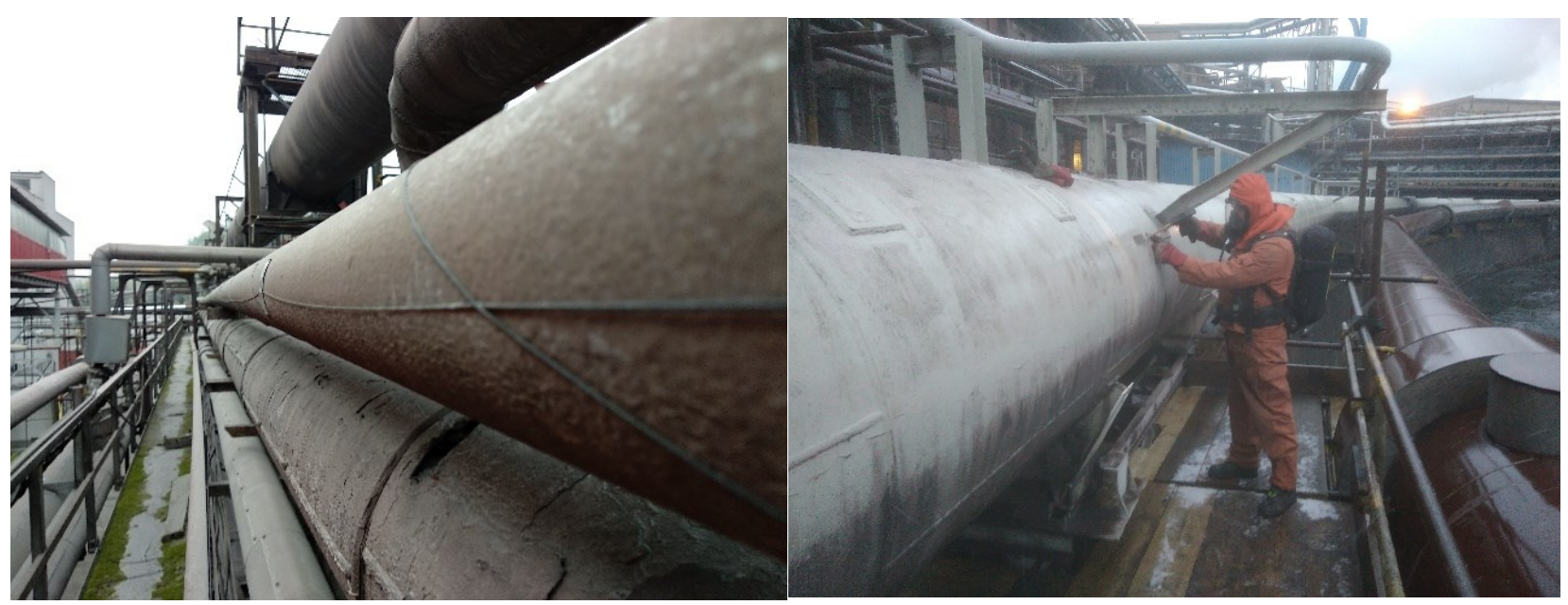

Figure 2. Mounting of optical fiber for pipeline monitoring

There is the optical fiber wounded around the pipeline, and the distributed temperature measurement via Raman scattering is used. The separate photonic application represents about $15-20 \%$ of the whole problém. The rest consists of safety questions, knowledge of installations, thermodynamics, heat transfer, knowledge of the properties of surroundings, pipelines mechanics, and so forth.

It is impossible to want the students could solve such problems, but they should know that these problems exist and without their successful managing, it is impracticable to apply this or another photonic system.

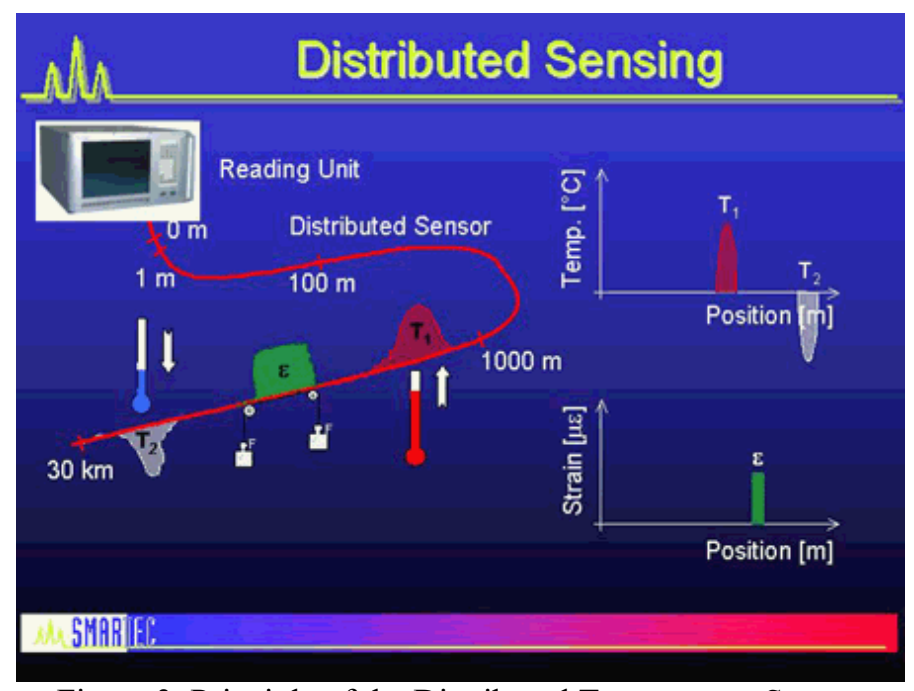

Figure 3. Principle of the Distributed Temperature System

It is very important for students to be aware of significant problems despite it is no direct relationship with photonics. What is functioning in the laboratory might not and usually does not working in the industrial application.

The searching for answers to such questions how to persuade the students about the importance of study not only the photonics but the other branches leads us to start a firm that is created with the same people as in university laboratory. Only economists completed the staff. 


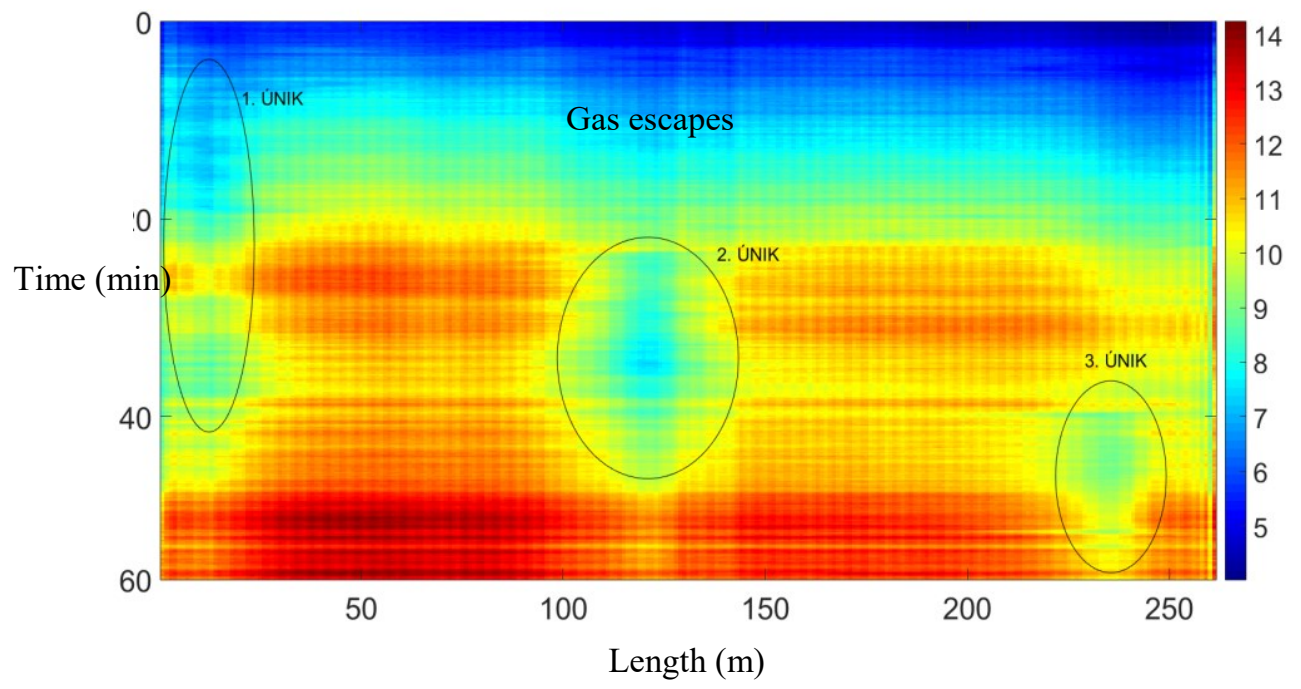

Figure 4. Monitoring results during the time

With the floatation of our firm, we created a quite new situation. Our students are working together with us; they do the same activities, Figures 3, 4. It means that our students meet their educators both during direct teaching but also during job orders and their solutions. What are the consequences?

1. The dominance of all educators increased rapidly.

2. Our students and graduates obtained the knowledge and skills that are important for their future occupation.

3. Students and graduates earn money due to highly professional activity.

4. The feelings of responsibility concerning results are highly increasing.

5. It acts about a unique combination of theory and practice.

6. The students and graduates understand easily the necessity to wider their knowledge and skills outside the photonics area.

7. The feeling of pride in results is increasing.

What types of job orders our students meet and solve?

a. Projects of fiber optical networks - transport, access, and structured.

b. Measurements of attenuation, dispersion, BER, wavelength into implemented lines including protocols from measurements.

c. Fiber optical distributed sensors for measurement and pipeline monitoring.

d. Fiber grating sensors for transportation, Fig.5, 6 .
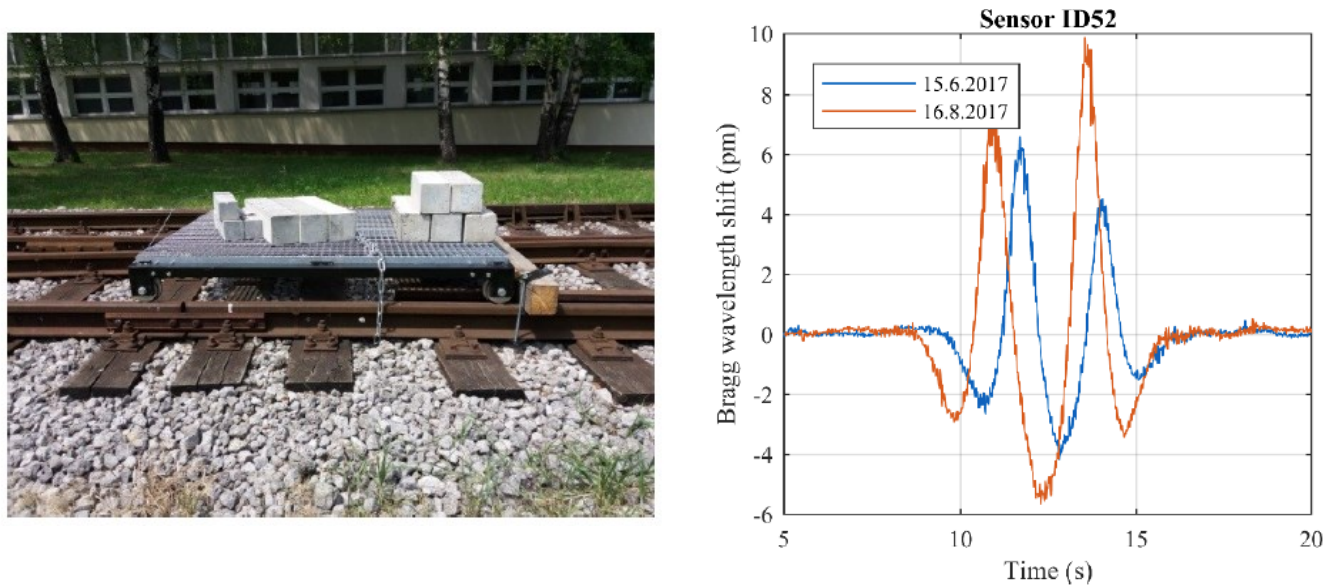

Figure 5. Fiber optical axle counter 



Figure 6. Monitoring of the train movements

e. Fiber grating sensors for medical applications, Fig.7, 8 .
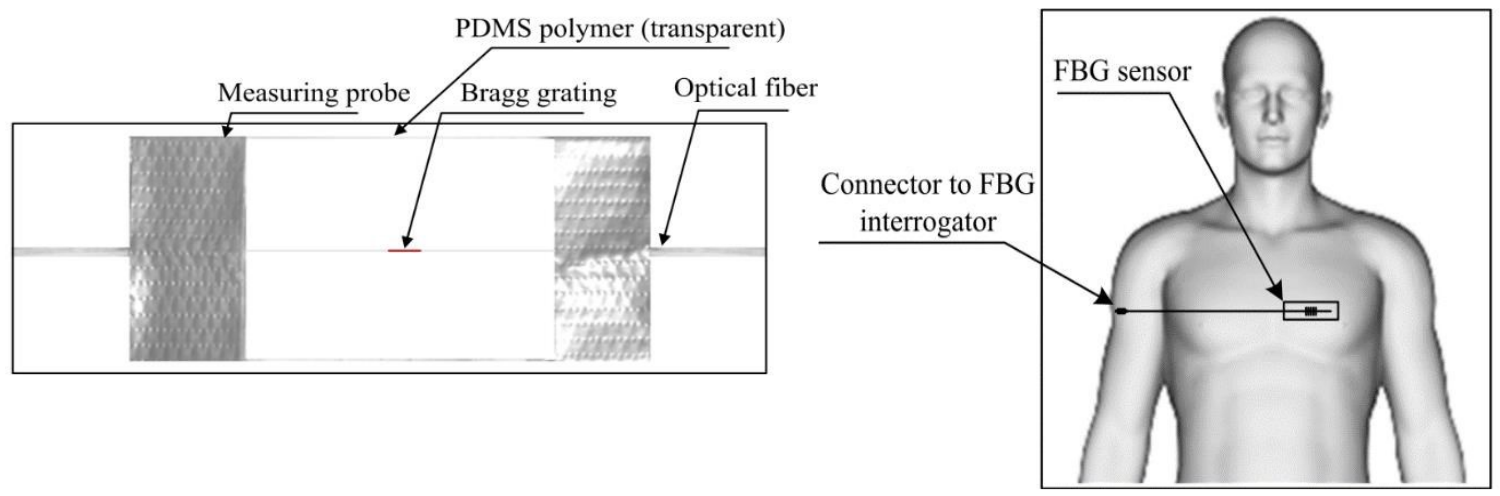

Figure 7. Monitoring of vital activity
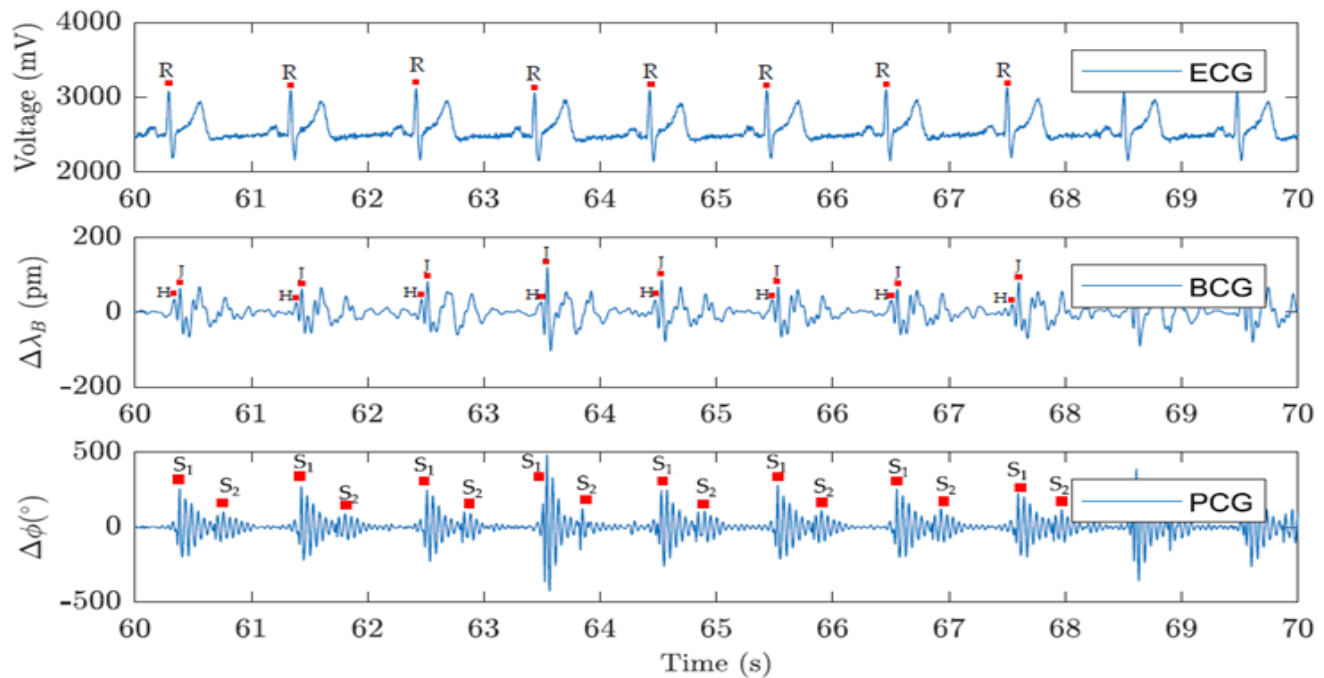

Figure 8. Signals of heart activity - upper, classic ECG, Bragg grating monitor, Michelson interferometer 
f. Microbending sensors for transportation control.

g. Measurements of electric current and magnetic field, Fig.9.
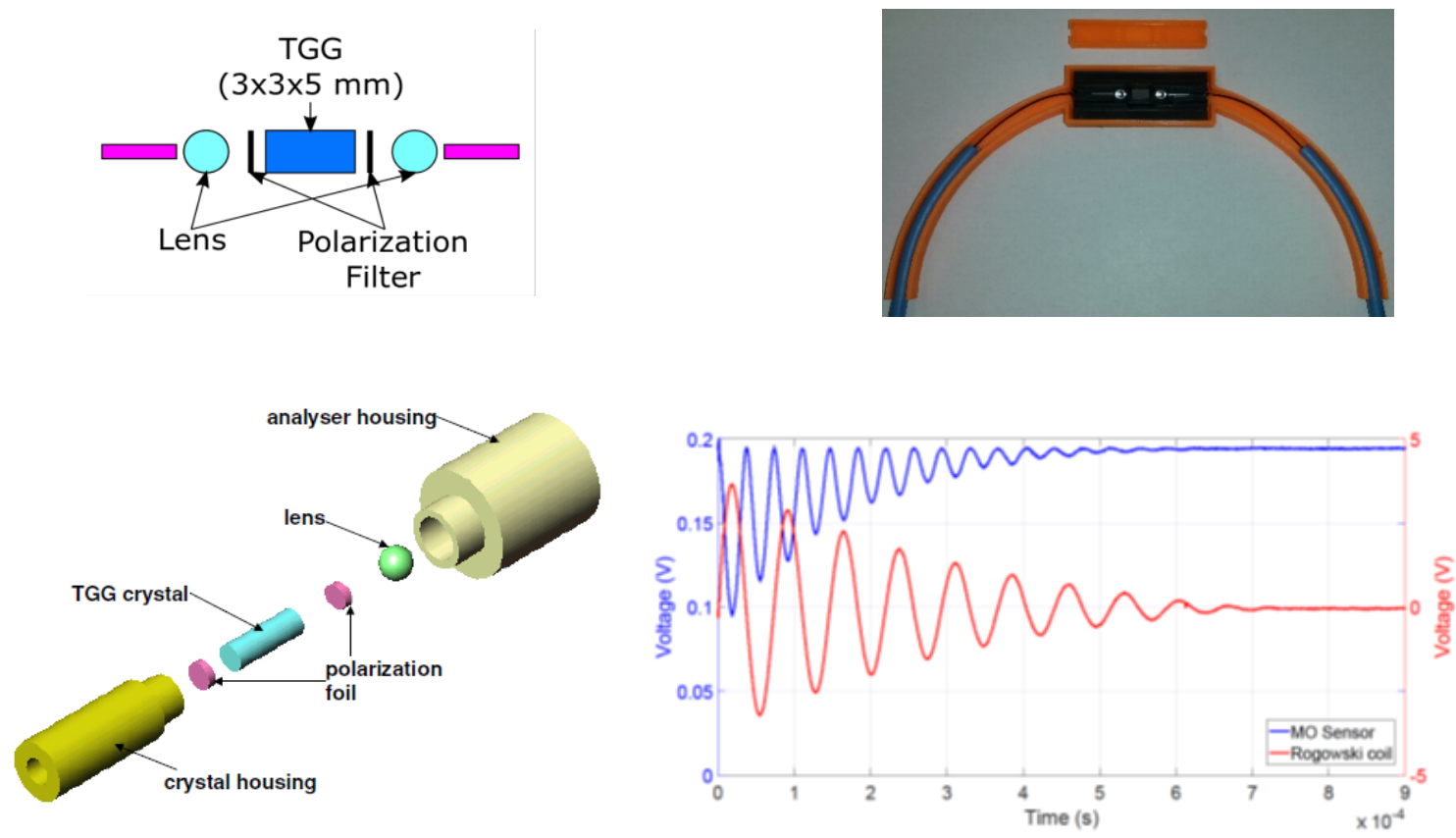

Figure 9. Fiber optical probe for magnetic field measurement (scheme, layout, real sensor, results)

h. Many special fiber optical applications.

\section{CONCLUSION}

The process mentioned above displays new possibilities for the joining firms and companies to the education process. As the best solution, it appears the tightest collaboration among students, graduates, and educators. This collaboration increases the knowledge and skills of students to a higher level; it helps to create humankind linkage among educators and students. Students are better prepared for their future jobs in the industry.

\section{ACKNOWLEDGMENTS}

Authors give thanks project FEECS SGS SP2019/80 for support.

\section{REFERENCES}

[1] Vasinek V., Siska P., Bednarek L., Latal J., Koudelka P. and Marcinka O.: Ageing of fiber optical devices.Next-Generation Optical Communication: Components, Sub-Systems, and Systems IV; San Francisco; United States, FEB 10-12, 2015, ISSN 0277-786X, $\mathrm{SNIP}=0,333$.

[2] Fajkus M., Nedoma J., Martinek R., Vasinek V., Nazeran H. and Siska P.: A non-invasive multichannel hybrid fiber-optic sensor system for vital sign monitoring. Sensors (Switzerland), 2017, 17(1).

[3] Papes M., Cheben P., Benedikovic D., Schmid J. H., Pond J. Halir R., Ortega-MOÑUX A., Wangüemert-Pérez G., Ye W.N., Xu D., Janz S., Dado M. and Vasinek V.: Fiber-chip edge coupler with large mode size for silicon photonic wire waveguides. Optics Express, 24(5), pp. 5026-5038. 2016.

[4] Vitasek J., Vasinek V., Latal J. and Hajek L.: Visible light communications with compound spectra. Optics Communications, 363, pp. 63-68. 2016. $20 \%$. 